\title{
REMOVAL OF ORGANIC POLLUTANTS FROM INDUSTRIAL CLEANING WASTEWATERS USING A COMBINED SEDIMENTATION AND PACKED-BED COLUMN TREATMENT
}

\author{
Sawanya Laohaprapanon ${ }^{I}$ \\ Marcia Marques ${ }^{2}$ \\ Fabio Kaczala ${ }^{1,3}$ \\ William Hogland ${ }^{1}$ \\ ${ }^{1}$ Linnaeus University, Sweden \\ ${ }^{2}$ Rio de Janeiro State University-UERJ, Brazil \\ ${ }^{3}$ The CAPES Foundation, Brazil Ministry of Education
}

\begin{abstract}
In the present study, organic removal from five industrial cleaning wastewaters generated at a wood-laminate floor industry in Sweden was evaluated using a combined treatment process including sedimentation and a packed-bed column of commercial wood-based activated carbon (WAC). The supernatant obtained from the sedimentation was diluted with tap water until the COD concentration was reached $5000 \mathrm{mg} / \mathrm{L}$ and it was continuously fed through the column by up-flow mode at a constant flow rate of $6 \mathrm{~mL} / \mathrm{min}$. The WAC performance at different bed height of 19,38 and $57 \mathrm{~cm}$ was studied. The results showed that the sedimentation process removed about $20 \%, 24 \%$ and $24 \%$ of COD, TOC and BOD, respectively and the WAC column was effective in removing COD from the water phase. The treated wastewater volume and service time increased with the bed height increase. The column could treat $19 \mathrm{~L}$ of wastewater with the service time of $63.3 \mathrm{~h}$ and $30 \%$ breakthrough point. The experimental data fitted well with the bed depth-service time (BDTS) model. The increase of wastewater load on solid phase from $20 \%, 30 \%, 40 \%$ and $50 \%$ showed an increase of sorption capacity $\left(\mathrm{N}_{\mathrm{o}}\right)$ and decrease of the rate constant $(\mathrm{k})$.
\end{abstract}

KEY WORDS: BDST model, bed height, COD removal, packed-bed column

\section{INTRODUCTION}

The study of wastewater pollution control has increasingly emphasized on small scale wastewater generators since it was found that although their discharge volume are low, it contains a significant organic pollution load released to the environment. The wood floor industry in Sweden, for instance, is known as a dry process factory due to the fact that the production processes have no water requirement. However, during cleaning procedures of indoors industrial floor and machinery used in different production processes such as wood sizing, glueing, filling and surface coating processes, there is a generation of small volumes of wastewater highly contaminated with adhesive chemicals (urea-formaldehyde and phenol formaldehyde resin), ammonium sulphate, wood filler, lacquer and detergents. Moreover, preliminary ecotoxicological assessments have shown that these wastewaters are extremely 
toxic to the algae growth [1]. Due to the low volumes generated, the construction of on-site conventional industrial wastewater treatment plants in this case is not appropriate from both economical and operational viewpoints. It is more practical for the company to dilute the wastewater with clean water or directly discharge to the sewage system. Those discharges may adversely affect the municipal wastewater systems and therefore, it is necessary to treat these wastewater streams preferably with a simple and cost-effective treatment process, in order to meet increasing regulatory demands posed by the local environmental authorities.

The removal of organic pollutants from wastewaters can be achieved by a single or several treatment technologies (biological, chemical and physicochemical treatment). Among the conventional treatment options, adsorption processes are found to be an effective method, since it has high pollution removal capacity, having simple design and also being ease to operate and maintain in full-scale [2]. It has been reported in the literature that the performance of sorption processes relies on many factors, such as: the composition of the wastewater, physical-chemical properties, adsorbent mass, and operating conditions [3]. In principle, the pollutants in the liquid phase can be adsorbed on the activated carbon by physical sorption or chemical sorption or both. Recently, sorption of organic pollutants from the same wastewater streams on wood fly ash obtained from a heating plant was studied in a batch system [4]. The results found that wood fly ash performed satisfactorily to remove COD from the wastewater. However, high leachatability of chromium from the wood fly ash is still in the question for a large scale implementation. In the present study, settling/ sedimentation as a pre-treatment step, combined with packed-bed column of commercial wood-based (WAC) activated carbons was studied by assessing the COD removal from a mixture of industrial wastewater streams generated by a laminate wood floor industry in laboratory scale.

\section{MATERIALS AND METHODS}

\subsection{Wastewater}

The wastewater streams originated from the following four different production units were studied: (i) sawmill process; (ii) glueing process; (iii) floor cleaning and; (iv) surface finishing process. Samples were collected immediately after the on-site cleaning was performed at a wood-laminate floor factory in Sweden. Samples of $20 \mathrm{~L}$ were collected each time and brought to the laboratory. Two litres from each stream were separated for further analysis and the remaining volumes were mixed using the same volume from each stream $(1: 1: 1: 1: 1)$ in a $100 \mathrm{~L}$ container. The mixture was kept during one week for sedimentation and the supernatant used for the column tests.

\subsection{Experimental set-up}

\subsubsection{Column study}

The packed-bed column of WAC used in the present study was built with PVC pipe. It has an inner diameter of $70 \mathrm{~mm}$, a height of $750 \mathrm{~mm}$ and a total bed depth of $570 \mathrm{~mm}$. The bottom of the column corresponding to $7 \%$ of total volume was filled with sand (particle size of 1-2 $\mathrm{mm}$ ). A peristaltic pump (VERDERFLEX, model: AU UV EZ) was used to feed the column with the wastewater from the bottom up to the top of the column. The effluent was collected from three different sampling ports that were equidistantly positioned along the columns (Figure.1). 


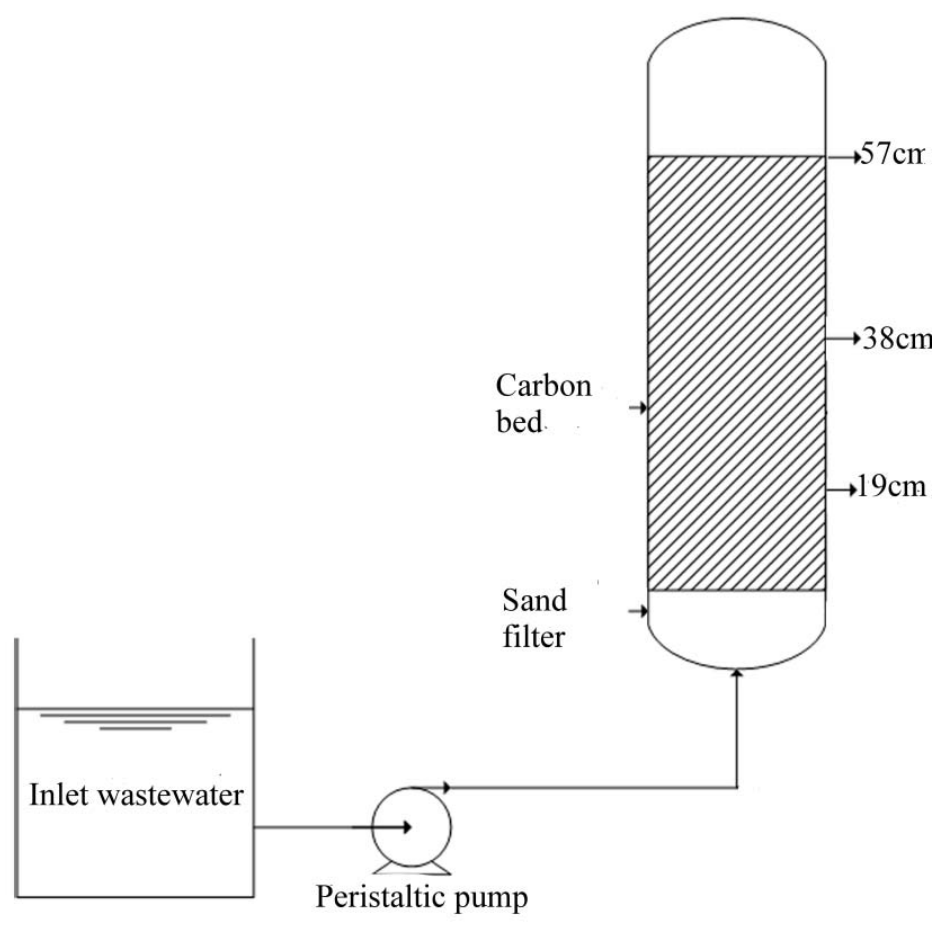

Figure 1 Schematic diagram of the packed-column used in the sorption studies.

Before the column studies were carried out, the void volume inside the column was completely filled with distilled water. When no air bubble could be observed from the column, the column was continuously fed with the diluted wastewater mixture $(5000 \mathrm{mg}$ COD/L), after settling/ sedimentation for one week, at the constant flow rate of $6 \mathrm{~mL} / \mathrm{min}$. The breakthrough curves of COD removal were studied at three different bed heights of 19 , 38 and $57 \mathrm{~cm}$, respectively.

\subsection{Analytical methods}

The COD and TOC concentrations were analyzed according to the methods LCK 114 and LCK 381 (Dr. Lange Dusseldorf, Germany). BOD 5 was analyzed according to ISO 5815 [5]. The $\mathrm{pH}$ in the solutions was determined by a portable $\mathrm{pH}$ meter (SG 2, Mettler Toledo).

\section{RESULTS AND DESCUSSION}

\subsection{Wastewater characteristics}

The wastewater streams generated during machinery and floor cleaning/washing procedures at the studied factory were frequently characterized from August 2009 to January 2010. It was found that the factory used to dispose an average of $1.0 \mathrm{~m}^{3}$ per week of all cleaning wastewater streams.. Based on COD, BOD and TOC concentrations (Figure 2), blade wastewater from sawmill process and floor cleaning wastewaters contained low organic pollution whereas, the filler wastewater from surface finishing process and glue and hardener wastewaters from glueing production unit were generally had high degree of pollution. 


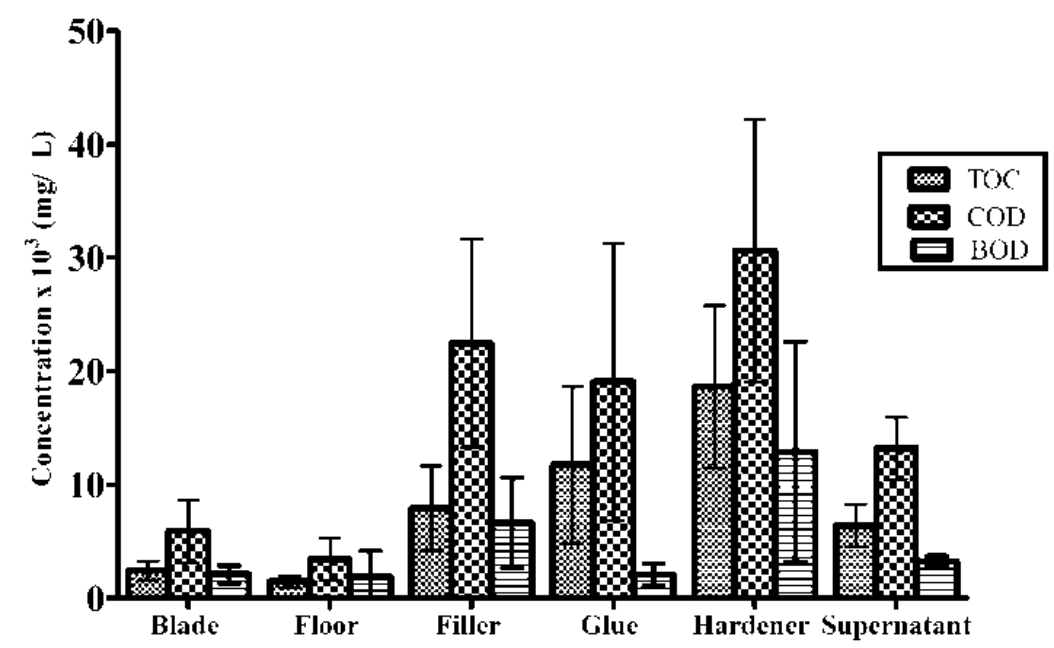

Figure 2 TOC, COD and BOD average concentrations in cleaning wastewaters generated from a wood-based industry $(n=5$ and bar $=S D$.)

The $\mathrm{COD} / \mathrm{BOD}_{5}$ ratio indicates the biodegradability of wastewater by microorganisms; the higher the ratio is, the less the biodegradability of the wastewater. Table1 shows that COD/ BOD $_{5}$ ratio of all cleaning wastewater streams (except for glue wastewater) was about 3, indicating moderate biodegradable wastewaters. The high $\mathrm{COD} / \mathrm{BOD}_{5}$ ratio observed in glue cleaning wastewater can be explained by a partial toxic effect of high formaldehyde concentration (up to $1500 \mathrm{mg} / \mathrm{L}$ ) in the wastewater on microorgamisms. Formaldehyde is commonly used as disinfectant in wastewater treatment plants. Because of its toxicity, even in low concentrations it can kill all microorganisms. Nevertheless, formaldehyde is biodegradable in both aerobic and anaerobic systems [6].

Table 1. Mean and standard deviation ( $n=5)$ of physicochemical characteristics of untreated wastewaters generated at a wood-floor factory and mixture of wastewaters after sedimentation during one week (COD, TOC, BOD unit of measurement $=m g / L)$.

\begin{tabular}{|c|c|c|c|c|c|c|}
\hline \multirow{2}{*}{ Parameter } & \multirow{2}{*}{$\begin{array}{c}\text { Floor } \\
\text { washing } \\
\text { (Floor) }\end{array}$} & \multirow{2}{*}{$\begin{array}{l}\text { Sawmill } \\
\text { process } \\
\text { (Blade) }\end{array}$} & \multirow{2}{*}{$\begin{array}{l}\text { Surface } \\
\text { finishing } \\
\text { process } \\
\text { (Filler) }\end{array}$} & \multicolumn{2}{|c|}{ Glueing process } & \multirow{2}{*}{$\begin{array}{c}\text { Mixture of } \\
\text { wastewaters }\end{array}$} \\
\hline & & & & (Glue) & (Hardener) & \\
\hline $\mathrm{pH}$ & $6.88 \pm 0.28$ & $12.50 \pm 1.73$ & $7.81 \pm 1.73$ & $6.17 \pm 1.13$ & $1.51 \pm 0.15$ & $2.70 \pm 0.12$ \\
\hline COD & $\begin{array}{l}4,091 \\
\pm 839\end{array}$ & $5,890 \pm 2,746$ & $22,460 \pm 3,778$ & $\begin{array}{c}19,044 \\
\pm 12,238\end{array}$ & $\begin{array}{c}30,600 \\
\pm 1,1524\end{array}$ & $13,197 \pm 2,743$ \\
\hline TOC & $1,446 \pm 502$ & $2,428 \pm 846$ & $7,920 \pm 3,717$ & $11,748 \pm 2,061$ & $18,629 \pm 7,151$ & $6,397 \pm 1,866$ \\
\hline BOD & $875 \pm 278$ & $1,861 \pm 746$ & $6,624 \pm 3,969$ & $6,936 \pm 1,019$ & $\begin{array}{c}11,920 \\
\pm 10,909\end{array}$ & $3,218 \pm 461$ \\
\hline $\mathrm{COD} / \mathrm{BOD}$ & $5.4 \pm 1.9$ & $2.9 \pm 0.7$ & $3.3 \pm 0.9$ & $9.5 \pm 2.2$ & $3.1 \pm 1.5$ & $3.8 \pm 0.1$ \\
\hline $\mathrm{COD} / \mathrm{TOC}$ & $2.9 \pm 0.4$ & $2.4 \pm 0.3$ & $2.9 \pm 0.4$ & $1.6 \pm 0.2$ & $1.7 \pm 0.1$ & $2.2 \pm 0.3$ \\
\hline
\end{tabular}


Considering the supernatant obtained by mixing all cleaning wastewaters in the same proportion (1:1:1:1:1) after sedimentation in the large container during one week, it was found that $\mathrm{COD}$, TOC and $\mathrm{BOD}_{5}$ concentrations were reduced in average in $20 \%, 24 \%$ and $24 \%$ respectively. These results suggest that an equalization and sedimentation tank should be constructed as a pre-treatment process in a full scale treatment plant.

\subsection{Column studies}

\subsubsection{Effect of bed height on breakthrough curves}

The breakthrough curves of COD removal were studied using the column packed with WAC at $2 \mathrm{~kg}$ for three different bed heights of 19,38 and $57 \mathrm{~cm}$. The column was fed with diluted cleaning wastewater from the bottom up to the top with a constant flow rate of $6 \mathrm{~mL} / \mathrm{min}$ (equivalent to $0.11 \mathrm{~cm} / \mathrm{s}$ ) and initial COD concentration was $5000 \mathrm{mg} / \mathrm{L}$. The results in Figure 3 showed that the breakthrough curves of COD removal by WAC were followed the typical "S-shaped" curves which indicated that sorbent was effective for removing COD from the studied wastewater. Similar breakthrough curves have been reported on adsorption of textile wastewater by GAC Filtrasorb 400 [2] and adsorption of basic dyes on to natural zeolite [7].

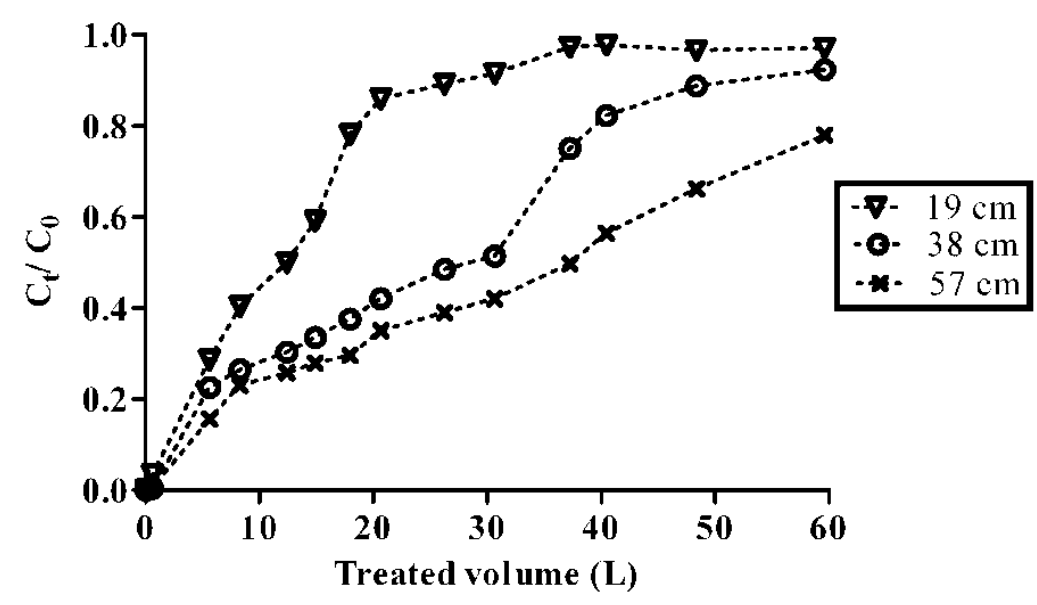

Figure 3 Breakthrough curves of COD sorption in wood-based activated carbon column.

Service time and treated wastewater volume were in general increased with bed height. As it can be observed in Figure 3, the treated wastewater volumes (corresponding to $\mathrm{C}_{\mathrm{t}} / \mathrm{C}_{0}=0.3$ ) were found to be 5.9, 12.4 and $19 \mathrm{~L}$ and the service time were 19.7, 39.0 and $63.3 \mathrm{~h}$ with 19 , 38 and $57 \mathrm{~cm}$ of bed height, respectively. The effect of the bed height on the service time during column studies has been reported by other researchers [7-9]. In deeper bed columns, the higher amount of activated carbons and consequently, higher amount of available sorptive sites are responsible for longer period needed to achieve the complete exhaustion of the sorbent material.

\subsection{Bed depth service time (BDST) model}

Bohart and Adam [10] developed the BDST model to study the performance of packed-bed column for treatment of any type of contaminant. The model expresses a relationship between bed height $Z$ (m) and time $t(\mathrm{~h})$ taken for a breakthrough to occur as shown in Eq. (1). 
$\ln \left(\frac{C_{Q}}{C_{b}}-1\right)=\ln \left(e^{K_{a} N_{\mathrm{e}} z_{F}}-1\right)-K_{n} C_{n} t$

The linear relationship of Eq. (1) is shown in Eq. (2) [9]

$\mathrm{t}=\frac{\mathrm{N}_{0}}{\mathrm{C}_{0} \mathrm{~F}} \mathrm{Z}-\frac{1}{\mathrm{C}_{0} \mathrm{~K}_{\mathrm{a}}} \ln \left(\frac{\mathrm{C}_{0}}{\mathrm{C}_{\mathrm{b}}}-1\right)$

Where $\mathrm{C}_{0}$ and $\mathrm{C}_{\mathrm{b}}(\mathrm{mg} / \mathrm{L})$ are respectively inlet and outlet of a contaminant concentration; $\mathrm{F}$ $(\mathrm{m} / \mathrm{h})$ is the flow rate per unit cross sectional area of column; $\mathrm{N}_{\mathrm{o}}(\mathrm{g} / \mathrm{L})$ and $\mathrm{k}(\mathrm{L} / \mathrm{g} . \mathrm{h})$ are the column adsorption capacity and rate constant respectively, which are obtained from the slope and intercepting point when plotting $t$ versus $\mathrm{Z}$.

Based on the experimental breakthrough data $\left(\mathrm{C}_{\mathrm{t}} / \mathrm{C}_{0}=0.3\right)$ using BDST model, the plot of the bed height against service time is illustrated in Figure 4. The linearization of the experimental data following equation 2 successfully described the treatment of cleaning wastewater using WAC $\left(r^{2}=0.996\right)$

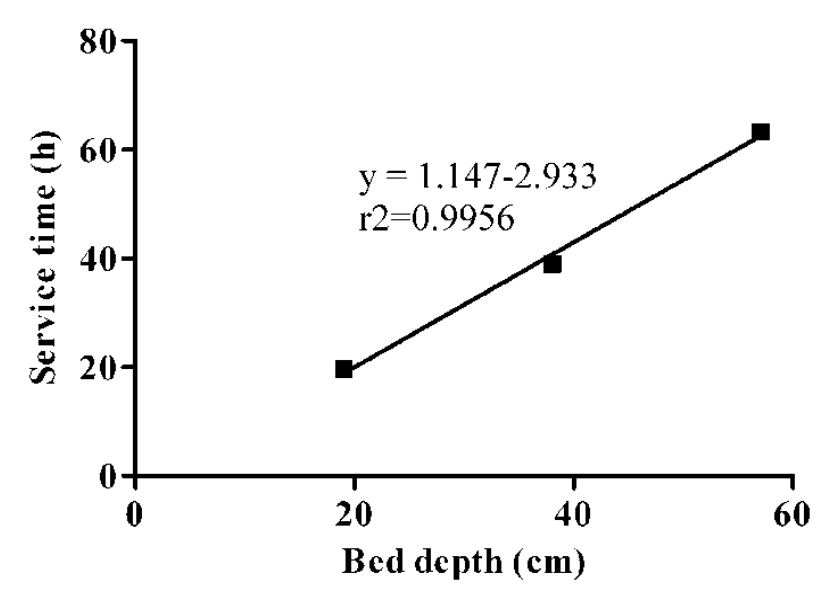

Figure 4. BDST model plot for COD removal at 30\% breakthrough point. Initial COD concentration $\left(C_{0}\right)=5000 \mathrm{mg} / \mathrm{L}$, Mass of activated carbon $=\mathrm{ca} .2 \mathrm{~kg} /$ column and feed flow rate $=6 \mathrm{~mL} / \mathrm{min}$.

The values of treated wastewater volume, $\mathrm{N}_{0}$ and $\mathrm{k}$ computed from the BDST model at different solid loading rates between $20 \%$ and $50 \%$ breakthrough points are summarized in Table 2. The amount of pollutants adsorbed on the bed increased when the breakthrough point increased with increase of sorption capacity $\left(\mathrm{N}_{\mathrm{o}}\right)$ and decrease of rate constant $(\mathrm{k})$. 
Table 2. BDST parameters for COD sorption through the packed column at the different break points and flow rate $6 \mathrm{~mL} / \mathrm{min}$.

\begin{tabular}{cccccc}
\hline $\begin{array}{c}\text { Breakthrough } \\
(\%)\end{array}$ & $\begin{array}{c}\text { Treated volume } \\
(\mathrm{L})\end{array}$ & $\begin{array}{c}\mathrm{N}_{0} \\
(\mathrm{~g} / \mathrm{L})\end{array}$ & $\begin{array}{c}\mathrm{N}_{0} \\
(\mathrm{mg} / \mathrm{g})\end{array}$ & $\begin{array}{c}\mathrm{k} \\
(\mathrm{L} / \mathrm{g} . \mathrm{h})\end{array}$ & $\mathrm{r}^{2}$ \\
\hline 20 & 7.2 & 18.00 & 55.4 & 0.7062 & 0.992 \\
30 & 19.0 & 57.37 & 176.5 & 0.0620 & 0.996 \\
40 & 27.3 & 94.09 & 293.3 & 0.0091 & 0.999 \\
50 & 37.3 & 133.6 & 411.1 & $\mathrm{ND}$ & 0.987 \\
\hline
\end{tabular}

ND: The value could not compute due to the positive intercept on BDST plot.

The BDST equation obtained from the present study can be helpful to scale-up the process for other concentrations and flow rates without experimental runs as it is explained in the following equations [11]:

A simplified form of the BDST model is

$t=a Z-b$

Where;

$\alpha=\frac{N_{0}}{C_{0} F}$

$b=\frac{1}{K_{a} C_{0}} \ln \left(\frac{C_{Q}}{C_{t}}-1\right)$

When the feed concentration is changed, a new slope, and a new intercept is given by the following expressions:

$a^{r}=a \frac{C_{0}}{C_{0}^{r}}$

$b^{s}=b \frac{C_{0}}{C_{0}^{s}} \frac{\ln \left(\frac{C_{0}^{s}}{C_{t}}-1\right)}{\ln \left(\frac{C_{0}}{C_{t}}-1\right)}$

Where $b^{r}, \mathrm{~b}$ are the new and old intercept and $C_{0}^{r}, C_{0}$ are the new and old influent concentration, respectively. New and old effluent concentrations are represented by $C_{t}^{s}$ and $C_{i}$, respectively.

The slope constant for a different flow rate can be directly calculated by Eq. 8

$a^{r}=a \frac{F^{*}}{F^{s}}$ 
Where a, $a^{r}$ are the old and new slope and $F$ and $F^{r}$ are the old and new influent linear velocity, respectively.

\subsection{Regeneration}

Most of the adsorption studies attempted to regenerate the saturated activated carbon in order to make the process more economical and feasible for application [12-13]. The preliminary results on the thermal regeneration of saturated WAC in the present study demonstrated that the adsorption capacity of saturated WAC can be recovered up to $90 \%$ of the virgin WAC using the thermal treatment at $500{ }^{\circ} \mathrm{C}$ for $30 \mathrm{~min}$.

\subsection{Proposal of a pilot scale treatment}

Based on the laboratory experimental study, the column sorption showed the potential economically and applicability treatment for organic removal from the studied machinery cleaning/washing wastewaters. The full scale on-site wastewater treatment for the studied factory is proposed and its diagram is illustrated in Figure 5. Due to the wastewaters are manually generated and their quantity and quality vary in time, a holding tank is suggested to be placed in the first treatment unit in order to equalize wastewater compositions and flow. The following step is a sedimentation unit which allows solid particles to separate from the liquid phase and prevent the clogging problem inside the column. It is important to highlight that the equalization tank for these wastewaters should made of $\mathrm{pH}$ resistant materials since the wastewaters has a wide $\mathrm{pH}$ range as it is reported in Table 1 and it should have an adequate volume for receiving all cleaning wastewaters discharge within the factory.

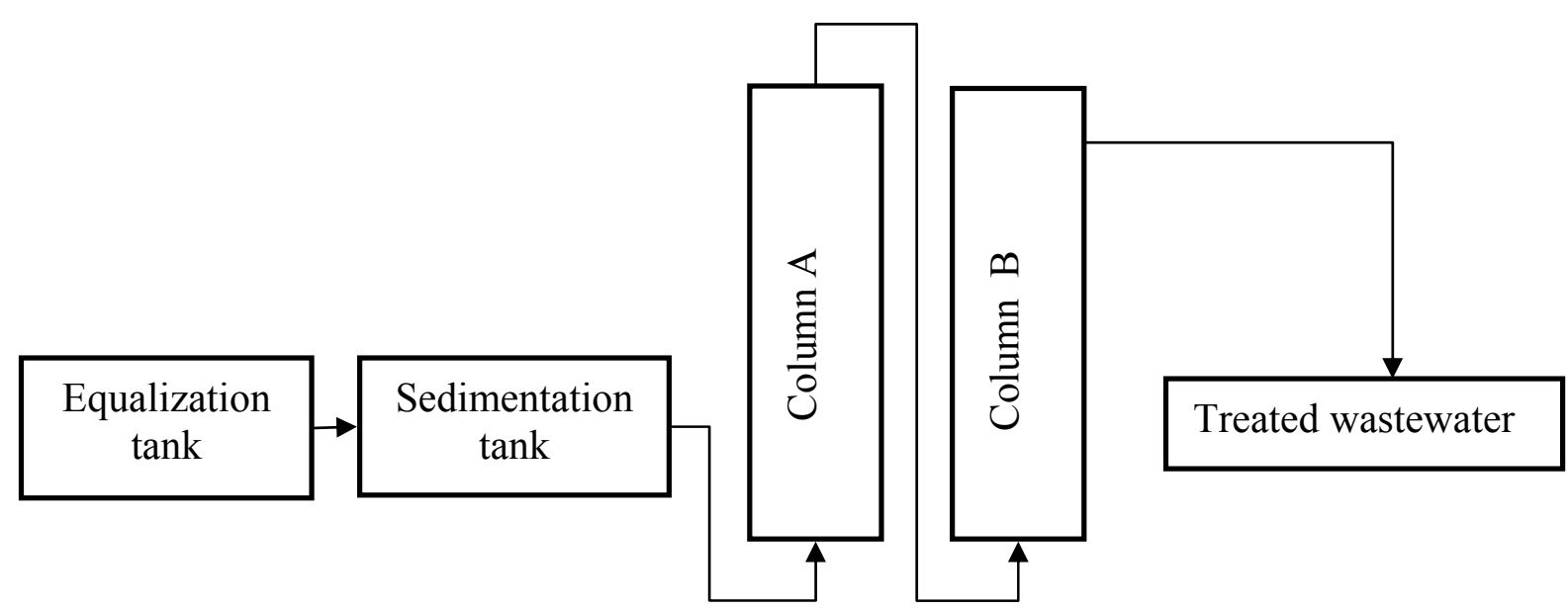

Figure 5. Simplified flow diagram of the proposed column treatment for cleaning/ washing wastewater at wood-based floor industry

The supernatant from sedimentation was continuously fed through the column that previously packed with wood activated carbon. The column should be designed to have a good liquid distribution system in order to avoid channelling inside the column during operation period. Moreover, it should have a suitable size to provide a good contact time between pollutants and WAC. As observed in the laboratory scale, the studied wastewater has high adsorption rate on the WAC during the first $30 \mathrm{~min}$. The treated wastewater should be collected occasionally for water analysis. 


\section{CONCLUSIONS}

On the basis of the experimental results of the present study, the following conclusions were formulated:

1) The results obtained with the equalization and sedimentation processes suggest that they should be included as a pre-treatment step for the cleaning wastewater studied, since they performed satisfactory in combination to the column treatment. One week of the wastewater mixture sedimentation promoted a reduction of COD, TOC and BOD at $20 \%, 24 \%$ and $24 \%$, respectively.

2) The wood-based activated carbon (WAC) can be used as a sorbent material for removal organic pollutants present in a mixture of real industrial cleaning wastewaters. The performance of the column packed with such sorbent was found to improve with the bed height and the increase of the sorbent mass.

3) The BDST model fitted to describe the sorption of organic pollutants measured in term of COD on wood-based activated carbon in column mode.

\section{REFERENCES}

[1] Laohaprapanon, S., Kaczala, F., Salomon, P.S,, Marques, M., Hogland, W., 2010. Effect of Industrial wastewater generated during cleaning/washing procedures in a wood-based industry on the microalgae Scenedesmus Subspicatus. Unpublished report, Linnaeus University, Kalmar, Sweden.

[2] Walker, G.M., Weatherley., L.R., 2001. COD removal from textile industry effluent: Pilot plant studies. Chem. Eng. J. $84,125-131$.

[3] Ho, Y.S., Ng, J.C.Y., , Mckay, G.,, 2000. Kinetics of pollutant sorption by biosorbents: Review. Separ. Purif. Meth.29(2), 189-232.

[4] Laohaprapanon, S., Marques, M.,Hogland, W., 2010. Removal of organic pollution from wastewater using wood fly ash as a low-cost sorbent. Clean-Soil, Air, Water 00(0), 1-7.

[5] ISO 5815. 1989. Water quality-determination of biochemical oxygen demand after $n$ days $\left(\mathrm{BOD}_{\mathrm{n}}\right)$, Part 1: Dilution and seeding method with allylthiourea addition, International Organization for Standardization: Geneva.

[6] Kaczala, F., Marques, M.,Hogland, W., 2010. Biotreatability of wastewater generated during machinery washing in a wood-based industry: COD, formaldehyde and nitrogen removal. Bioresour Technol. 101(23), 8975-8983.

[7] Markovska, L., Meshko, V., Noveski, V., 2001. Adsorption of basic dyes in a fixed bed column. Korean J. Chem. Eng. 18,190-195.

[8] Al-Degs, Y.S., Khraisheh, M.A.M., Allen, S.J., Ahmad, M.N., 2009. Adsorption characteristics of reactive dyes in columns of activated carbon. J. Hazard. Mater. 165, 944949.

[9] Vijayaraghava, K., Prabu, D., 2006. Potential of Sargassum wightii biomass for copper (II) removal from aqueous solution: Application of different mathematical models to batch and continuous biosorption data. J. Hazard. Mater. B137, 558-564.

[10] Bohart, G.S., Adams, E.Q., 1920. Adsorption in Columns, J. Chem Soc. 42.

[11] Han, R., Wang, Y., Zhao, X., Wang, Y., et al. 2009. Adsorption of methylene blue by phoenix tree leaf powder in a fixed-bed column: experiments and prediction of breakthrough curves. Desalination. 245, 284-297. 
[12] Miguel, G. S., Lambert, S. D., Graham, N.J.D., 2001. The regeneration of field-spent granular-activated carbons. Water Res. 35(11) 2740-2748.

[13] Zhang, H.P., 2002. Regeneration of exhausted activated carbon by electrochemical method. Chem. Eng. J. 85, 81-85. 